\title{
Negotiation of Individual and Collective Identities in the Online Discourse of Autistic Adults
}

\author{
So Yoon Kim, MA, and Kristen Bottema-Beutel, PhD
}

Background: Previous studies have shown an increasing preference for online communication within the autistic advocacy community. Yet, little is known about how online communication facilitates the formation of autistic identity. This qualitative study examined online autobiographical narratives about repetitive and restricted behaviors - specifically "stimming" - produced by autistic adults. The primary goal of this study was to investigate how the production of, and online interactions around, these narratives functioned as collaborative resources for empowered autistic identities.

Methods: Nine blog posts were located that contained autobiographical narratives related to stimming and were analyzed using discourse analysis.

Results: Analysis revealed that individual and collective identities were negotiated within narratives through: (1) situating the self in relation to other story characters and the reader in varying ways and (2) connecting the autistic community and solidifying collective ideologically aligned voices.

Conclusions: Online blog spaces facilitated the emergence and construction of empowered individual and collective identities for autistic individuals. Future research should continue to focus on how autistic individuals form relationships, create advocacy communities, and cultivate empowered identities within online spaces.

Keywords: narrative, identity, discourse analysis, autism, online communication

\section{Lay Summary}

Why was this study done and what was the purpose of this study?

More autistic individuals are using the internet to communicate, and research has shown that online communication can benefit autistic individuals in various ways. However, there is a lack of understanding of how online communication is related to autistic identity. We examined how autistic bloggers' stories about their stimming experiences contributed to individual and collective autistic identities. Stimming refers to repetitive body movements, movements of objects, and other repetitive and restricted behavior and is considered one of two core features of an autism diagnosis. Although some stakeholders such as educators or parents have tried to get rid of these repetitive movements because they believe that stimming is not an appropriate behavior, autistic and other neurodiversity advocates assert that stimming is beneficial for autistic individuals and is important for developing an autistic identity.

What did we do?

We examined nine blog posts written by autistic bloggers using a method referred to as discourse analysis. In each blog post that we analyzed, the author shares their experiences about stimming. Discourse analysis is a method used to explore how people use language to build meaning, including the formation of social identities. Therefore, particular attention was paid to how the bloggers told the narrative (i.e., specific word choices to describe characters within the narrative and verb tense).

What were the results and implications of the study?

We found that by sharing stories about their stimming experience in the context of blog posts, autistic individuals developed empowered individual and collective autistic identities and challenged dominant and neurotypical social norms. Also, within online space, autistic individuals formed social relationships and connections that contributed to a collective identity. More research on how autistic individuals develop supportive relationships and form advocacy communities within online spaces is needed to promote emotional well-being and overall quality of life in this population.

Department of Teacher Education, Special Education, and Curriculum and Instruction, Lynch School of Education, Boston College, Chestnut Hill, Massachusetts. 


\section{Introduction}

$\mathbf{P}$ REVIOUS STUDIES have described a growing preference for internet and computer-mediated communication (CMC) within the autistic community. Specifically, previous research showed that online spaces supported autistic individuals in constructing social relationships ${ }^{1}$ and participating in community conversations. ${ }^{2}$ This may be because CMC provides a safe environment where autistic individuals can communicate without the social pressure of real-life interaction and the need to understand subtle nonverbal cues that may be required in face-to-face interactions. ${ }^{3}$ Furthermore, having access to online interactions allows autistic individuals to connect with one another, collectively oppose organizations and biomedical discourses that they deem oppressive or even abusive, and advocate for neurodiversity. ${ }^{3}$

The neurodiversity movement reconceptualizes autism spectrum disorder (ASD) as a way of being and an integral component of personal identity. Moving away from expert discourses about ASD, which characterize autistic adults as victims requiring treatment and as passive recipients of support, ${ }^{3}$ the neurodiversity movement appreciates the various neuropsychiatric characteristics of people who are on a diverse spectra of support needs. ${ }^{4}$ Davidson $^{3}$ claimed that CMC has supported the emergence of the neurodiversity movement by facilitating the rejection of reductive characterizations of ASD while supporting the development of an autistic cultural identity.

Meanwhile, advocacy blog posts are sites of struggle and support composed of connected advocacy discourse. Clark and Van Amerom ${ }^{5}$ have shown how autistic bloggers address problems, identify with the ideals to which advocates are oriented, and communicate the proudness and value of their experience of autism on their blog posts. Blog posts are any piece of writing or other forms of content published on a blog where writers express their opinion and perspectives on an issue to a general audience. ${ }^{6}$ They are different from discussion groups in terms of accessibility; they tend not to restrict readership to registered members of a group. There is currently a need for research exploring the identity work with which autistic adults in online spaces engage, as a part of an emerging autistic advocacy culture. This study examines online blog posts produced by autistic adults that present narratives involving self-stimulatory movements or "stimming," a specific type of repetitive and restricted behavior (RRB). Specifically, we examine the discursive strategies employed by autistic individuals in online spaces, as they share their experiences of stimming, and pay particular attention to how these narratives contribute to identity development.

While researchers agree that the internet has benefited the autistic community in various ways, only a few studies have investigated how online discourse supports the achievement of empowered identities in the autistic community. Existing literature tends to focus on identity work within online chat groups with a restricted membership, in which only approved members may contribute postings and access the archives. For instance, Brownlow and O'Dell ${ }^{1}$ showed how online chat groups served as a powerful tool in establishing the status of autistic individuals as autism experts and voicing their concern about identities and terminologies used to label them. Also, autistic individuals in the discussion groups negotiated their empowered identity by collectively rejecting concep- tualization of autism as "abnormal" and therapeutic interventions that attempt to normalize autistic behaviors. ${ }^{7} \mathrm{We}$ extend this work to public blog postings.

\section{RRBs and disability identity}

RRBs consist of repetitive hand or whole-body movements, perseverative actions, play routines, or behaviors. ${ }^{8}$ RRBs are currently considered a key diagnostic criterion of ASD, representing one of two domains of impairment. ${ }^{8}$ Furthermore, some clinical definitions consider RRBs as idiosyncratic behaviors, which need to be reduced to improve social functioning. ${ }^{9}$ Previous studies have identified the negative influence of stereotypic behaviors on the acquisition of new skills, ${ }^{10}$ engaging in positive social interactions, as well as its contribution to the stigmatization of ASD. ${ }^{9}$ Thus, the reduction of stereotypic behaviors has been a focus of ASD intervention research for several decades. ${ }^{11}$

While researchers have categorized RRBs as problematic ASD symptoms that need to be extinguished, autistic advocates argue for a different viewpoint. Steward ${ }^{12}$ contended that motor RRBs have adaptive functions such as relieving anxiety and protecting autistic individuals from sensory overstimulation. Also referred to as "stereotypy" by researchers and psychiatrists, within the autistic community this repetitive motor movement is more frequently and commonly referred to as stimming, a neologism derived from the phrase selfstimulation. Although we were not able to locate any literature tracing the etiology of the word, it is generally understood that applied behavioral analysis (ABA) therapists first started using the term to refer to problematic behaviors that need to be eliminated by extinction and/or reinforcement.

Online narratives about stimming were chosen as the data source for this analysis because autistic advocates frequently refer to stimming when they are discussing their autistic identity. Unlike difficulties in social interaction, stimming is deemed an inherent part of autistic identity, not something autistic individuals choose to do or want to change. ${ }^{13}$ Stimming does not in and of itself bear moral significance, yet it can be stigmatizing and perceived as socially inappropriate. Narratives about stimming can illustrate divides between individuals who want to be accepted as they are, and nonautistic "clinical, popular, or parental"3(p791) perspectives. The accounts of stimming from this second group tend to reinforce stigmatized images of autistic individuals and prioritize efforts to make autistic people "less autistic."

\section{Loud Hands Project}

"Quiet Hands," a blog post by Julia Bascom ${ }^{14}$ published online in 2011, describes her childhood experiences of hand flapping and the abusive measures taken to stop this behavior, such as trying to hold her hands down with tacky glue. This post received dramatically positive responses from the autistic community and has been tweeted, retweeted, and quoted in online advocacy blogs, which invited others to share their own stories. Sharing her stimming experiences online gave rise to a more formalized advocacy movement called "The Loud Hands Project." This project culminated in Loud Hands: Autistic People, Speaking, a book of essays depicting experiences with and responses to the bullying, marginalization, and abuse often inflicted on autistic individuals. ${ }^{15}$ Several advocates have attested to the influence of Bascom's "Quiet Hands" on the 
general awareness of the topic and on the initiation of the Loud Hands Project. ${ }^{16}$ The Loud Hands Project is meant to inform the general public while supporting the development of a systematic and safe community. ${ }^{17}$ Bascom's "Quiet Hands" blog post served both to initiate the Loud Hand Project and as a jumping off point for most of the stimming narratives we examined in this article.

\section{The current project}

Through the examination of stimming narratives, this article explores how online autistic advocacy contributes to autistic identities. We use Ochs and Capps' discourse analytic work ${ }^{18}$ on narrative practice and identity formation as a framework for our analysis.

Autobiographical narratives exceed mere reiteration of events by their capacity to reveal the narrator's memory of how an event occurred as well as what it means to the speaker and why it is important. ${ }^{18}$ By providing an opportunity to self-reflect, the articulation of past experience is central to identity formation. ${ }^{19}$ During narrative tellings, individuals organize their experiences into a coherent and temporal structure, which plays a role in configuring their current identities. ${ }^{18}$ Through narration, the individual can resolve discordant past events and relate them in a meaningful way to former and current selves, thereby attempting to create a consistent sense of self. ${ }^{18}$

Identities are also created and transformed within socially situated interaction between the audience and teller. ${ }^{20}$ Som$\mathrm{ers}^{21}$ contended that tellers shape their identities through performative and interactional aspects of narrating events, which comes into existence through engagement with the audience. Therefore, identity is a relational construct that emerges in and through interaction. ${ }^{20}$ The relationship between the speaker and audience is often particularly salient in blog conversations, compared with other forms of written text, as readers are able to interact with bloggers by leaving comments in response to blog posts. Furthermore, the dynamic nature of blogs can extend beyond the local interaction between a teller and audience to the presentation of self within a community. ${ }^{22}$

Narrators draw from an array of grammatical, linguistic, and discursive resources to perform narrative tasks such as contesting or expressing alignment on societal issues. ${ }^{18}$ For example, narrators can manipulate verb tenses to position their behaviors as independent or obligatory, thereby representing what Capps and Ochs ${ }^{23}$ referred to as agentiveness-being an owner of one's own behaviors and thoughts-or conversely, passivity. ${ }^{22,23}$ Depending on the specific linguistic resources narrators mobilize, narrators can continually change how they and others are represented in the narrative. ${ }^{20}$ Communicating and reproducing the relevant texts that comprise the overlapping perspectives on social practice enable construction of social identities within and across the discourse community and thereby facilitate the textual construction of collective identities. $^{24}$ Identities are embedded in sociocultural and historical circumstances, as well as particular ideological and institutional social structures. ${ }^{25}$ Therefore, in our analysis of autistic narratives, we attend to discursive and indexical elements that reference wider sociocultural expectations in regard to stimming in particular, and conceptions about ASD more generally.

\section{Methods}

\section{Data source}

Using combinations of the keywords: autism, Asperger, neurodiversity, advocacy, stimming, experience, RRBs, Loud Hands Project, and story, a web search was conducted in Google and yielded four blog posts featuring autobiographical narratives related to motor movements. A snowball sampling method was employed to locate as many relevant narratives as possible, as links and references from each post were followed to identify other potentially relevant texts. We also traced comments on the four identified blog posts that led to the commenter's own blogs, where commenters often wrote their own narratives of the past experiences with stimming behaviors. Also, blogs frequently included a list of recommended blogs or blog posts, and these lists have also been searched.

While RRBs include behaviors other than repetitive movements, ${ }^{26}$ we specifically focused on repetitive body movements, movements of objects, and vocalizations, collectively referred to as "stimming." Narratives on stimming were chosen because the autistic individuals do not reference other types of RRBs, such as insistence on sameness or restricted interests to discuss their autistic identity and rights. The selection criteria included any autobiographical narrative about stimming produced by adults who identify as autistic, regardless of the presence of formal diagnosis, the types of source materials (e.g., blogs, discussion group), or the authors' acceptance of the neurodiversity framework. Nine blog posts were included in the final analysis, and one blogger, Ms. Julia Bascom, contributed two blog posts to the data set. We contacted all identified bloggers, asking for their suggestions for other blog posts that included narratives on stimming experiences. We received one response from a blogger, who had no further suggestion other than the list in her blog, which had already been searched. The final data sample primarily consisted of blog posts created by autistic self-advocates because these materials comprise the data set we were able to locate using our Google search and snowball sampling method. It is possible that writings of relatively vocal self-advocates who frequently and regularly share their perspectives on their blogs are more readily available than works of individuals who are less active in sharing and writing about their concerns and experiences. Table 1 provides a list of texts and bloggers included in the current analysis.

\section{Ethical issues}

We approached this project with care, and with an understanding that we were using sensitive personal narratives as an object of study. We restricted data collection to publicly available and searchable blogs and sought to honor the voices of the narrators that were included in our analysis. Fleischmann and Miller ${ }^{27}$ and Marcus et al. ${ }^{28}$ provided guidelines to select publicly accessible blogs of online narratives produced by adults with Attention-Deficit/Hyperactivity Disorder and youth with various mental health concerns, respectively. For this study, we adapted their guidelines to include the following two criteria for inclusion: the online content (1) did not require registration or permission for accessing the site or for leaving comments and (2) has been viewed more than 200 
Table 1. Included Blog Posts

\begin{tabular}{|c|c|c|}
\hline Blog title & Post title & Author \\
\hline Just Stimming... & Quiet Hands & Julia Bascom \\
\hline Just Stimming... & Response & Julia Bascom \\
\hline Yes, That Too & My decision, not yours & Alyssa Hillary \\
\hline Autistic Hoya & Having Loud Hands & Lydia Brown \\
\hline The Caffeinated Autistic & On Stimming and why "quiet hands"ing an Autistic person is wrong & Rose J. \\
\hline Love Explosion & The cost of compliance is unreasonable & Maxfield Sparrow \\
\hline The Artism Spectrum & Stimming 101, or: How I learned to Stop Worrying and Love the Stim & Kirsten Lindsmith \\
\hline A Post-Structural Autistic & THAT'S NOT WHAT MAKES ME CRAZY, PART 2 & Erika Lynn \\
\hline Autistic Experience $^{\mathrm{a}}$ & Stimming Experience $^{\mathrm{a}}$ & Laura Jo ${ }^{\mathrm{a}}$ \\
\hline
\end{tabular}

${ }^{\text {a }}$ Pseudonym was created to refer to one blogger from whom we do not have explicit permission.

times. In addition, we reached out to all eight bloggers to request permission to reference their blog title and screen name and received explicit permission from all but one blogger who did not respond to our e-mail requests. We included the blog post of the blogger who did not respond to us because it was considered a publically accessible document. For this blogger, we used a pseudonym. We would have honored requests not to include blog posts in our analysis had this been asked of us (none of the bloggers requested this).

\section{Data analysis}

The first author is a doctoral student studying autistic individual's transition to adulthood. The second author is a professor of special education specializing in the interaction dynamics of autistic children and adolescents. We both approached the data corpus through a neurodiversity lens and believed that the voices of autistic individuals need to be valued in research, and also when making decisions about interventions or support systems. No doubt, our positionalities influenced each stage of the research process, including forming the research questions, selecting analysis methods, analyzing extracts, and interpreting findings.

The first author collected the data corpus and reviewed the data in an initial pass to identify various grammatical, discursive, and contextual features relevant to identity formation in narratives. Subsequently, the first and second author compared the grammatical, discursive, and contextual features that emerged from the initial pass against the data corpus to isolate and organize potential domains of discursive moves based on the types and the purposes of different discourse features. The identified domains were then consolidated and reconstructed into two overarching phenomena: (1) situating the self in relation to story antagonists and to the reader and (2) mobilizing webspace (e.g., the blog posts and their comments) as a resource for constructing a collective identity.

Segments that clearly illustrate each of these domains were selected as representative examples and are included in the text below. Nonbinary pronouns (singular use of they/them/ theirs instead of she/her/hers or he/him/his) are used to refer to some bloggers who explicitly expressed their preference during the e-mail correspondence. As is common in many discourse analytic studies, findings and discussion are presented together in a single section.

\section{Findings and Discussion}

\section{Situating the self}

First, we illustrate how tellers situate the story "self" relative to other story characters and to the reader. Tellers mobilize resources such as manipulating verb tenses, describing antagonists as depersonalized authority figures, and giving or withholding speaking roles to different characters. Finally, the tellers position themselves as dynamic agents, who can directly address, advise, and admonish the readers.

Situating the self in relation to story antagonists. Verb tenses. In the narratives we examined, tellers differentially situated story antagonists in relation to their past selves on the one hand and current selves on the other hand. When narrating about experiences as children, protagonist-selves were grammatically positioned as the object of the speech, acted upon by antagonists in positions of authority. For instance, in Example 1, Lynn $^{29}$ recounted their experience as a child when they were told to stop stimming:

\section{Example 1}

For example, as a kid, my family would make me sit on my hands, or make me restrain my body in other ways to stop from stimming. ... In school, I was told not to stim (fidget was their word) because it was considered disruptive.

In this example, the protagonist is the passive agent or object in relation to antagonist actions, being "made" and "told" to control their own behavior. These verb-object phrases exemplify what Van Leeuwen referred to as passivation, in which the teller is represented as being "at the receiving end of [the action]."30(p44) Similarly, Capps and Ochs ${ }^{23}$ described how the most obvious grammatical strategy for conveying helplessness is to enact a passive nonagentive character.

Similar examples abound in our data set; in Example 2, Rose $^{13}$ described their past experience on stage for a choral performance, during which they were scolded by the choral director for rocking and flapping:

\section{Example 2}

When my choral director pulled me aside and scolded me, telling me I was "disrespectful" and "an embarrassment" to my school. 
In Example 3, Jo recounts an incident as a child when her mother saw her jumping and flapping at a shopping center:

\section{Example 3}

She pulled me aside, and in frightened tones, told me that I shouldn't flap my hands. Only infants did that, she said, and people who were mentally retarded ... In ninth grade Geometry, one exasperated girl threw peanuts at me until I shut up.

The characterization of antagonists and their behaviors toward the tellers references dominant ideologies that permit autistic children to be treated as passive recipients of actions upon them. The story antagonists hold authority to verbally and sometimes physically suppress the narrators' stimming in public spaces. The tellers were expected to conform to these instructions or risk broader social sanctions, such as being labeled "disrespectful," "an embarrassment," or "mentally retarded."

In contrast, several narratives end with the narrator's current resistant self, such as Lynn's ${ }^{29}$ illustration of their transformed positioning as an older self who is directing their own activities as they reintroduce their stimming as empowering and natural:

\section{Example 4}

As I began to realize that I was Autistic ... it became empowering for me to stim ... I'm so much better able to deal with my outside world and environment in large part because I feel much more free to express my feelings and regulate my emotions.

Here, the narrator at present is articulated as a volitional agent who is "expressing," "realizing," and "being able to deal" with their own behavior, which is in sharp contrast to the passive tense used in scenes set in the past, where Lynn is the recipient of actions. Through the use of different verb forms and tenses across recollections set in the past and present, Lynn illustrated a changed identity from a passive participant who is being told to stop stimming into an active agent with newfound power and an ability to comport themselves how they please.

Describing antagonists. Narrators regularly portrayed antagonists as generalized authority figures who are older than the past self of the teller. For example, Bascom ${ }^{14}$ recounted her childhood experience when she was physically forced to stop stimming:

\section{Example 5}

When I was six years old, people who were much bigger than me with loud echoing voices held my hands down in textures that hurt worse than my broken wrist while I cried and begged and pleaded and screamed.

In Example 6, Jo uses general membership categories to refer to individuals who rejected to her stimming:

\section{Example 6}

I find it ironic that when my teachers and parents told me to stop stimming.
Such descriptors as "people who were much bigger with loud voices," "their" (referring to a generalized authority), "my parents," and "my teachers" connote institutional authority and thus amplify the antagonists' dominance over the past self. Except for instances when the tellers are talking about their mothers, the antagonists are referred to as their profession or position in a society such as teachers or a choral director, rather than being nominated with a specific name.

Sometimes, portions of the narrative are written in the passive voice, so that the narrators are positioned as subjects of an unnamed actor. For example, Lynn $^{29}$ wrote in the passive voice, "in school, I was told not to stim (fidget was their word) because it was considered disruptive." In an analysis of personal media accounts of cosmetic plastic surgery patients, Figueiredo showed how tellers' description of "others" in narrative can index a generalized archetype of beauty; "typical white, neo-liberal, middle-class heterosexual" $31(\mathrm{p} 256)$ females. Similarly, in online narratives of childhood stimming, antagonists who attempt to suppress stimming are positioned as a generalized authority or sometimes as an institution rather than specific identifiable individuals. This imprecise portrayal of the antagonist references the nonautistic ideal endorsed by the dominant and nonautistic society, and pervasive social norms that are extensions of the story antagonist.

Character voice. Along these same lines, while the tellers rarely give themselves a speaking role within the narratives in past-self narratives, they often give other characters voices through quoted sentences or words. This served to represent ideologies about what is acceptable, and position these as against their own character-self. For example, the other characters in Examples 2 and 3 are quoted as using language such as "disrespectful," "an embarrassment," and "mentally retarded" to describe the teller's past self or the teller's stimming from the past. In Example 2, after describing their humiliation at hearing the words of the choral director, the teller assumes their present perspective as narrator to reject the viewpoint imposed upon them as a child by rhetorically questioning why they should have to live up to neurotypical standards. In Example 3, the teller uses her mother's voice to present an ideology that jumping and flapping in public is acceptable only when practiced by infants or mentally retarded people. Then, the teller as her present self evaluates the experience, not as a character of the narrative but as a teller noting that this incident was an exception to her mother's otherwise respectful treatment.

Similarly, $\mathrm{Kim}^{32}$ found that informants in his study on "coming-out stories" were able to invoke the conservatism of traditional Asian parents against gay/lesbian identities by voicing the family's concern and treating the comments "as a challenge to the teller" and oppositional to the informants' opinions. The blog posts we examined also show the ability of the tellers to use these linguistic resources to contrast their ideology with the antagonists' and negotiate their agentive individual identities in contrast to society's conception of what is "normal."

Situating the self in relation to the reader. In addition to positioning their protagonist-self in relation to story antagonists, narrators also situated themselves vis-à-vis an imagined or eventual reader. In Example 7, Rose ${ }^{13}$ used the secondperson plural pronoun "you" to reference those who enforced quiet hands upon them as children: 
Example 7

It's the equivalent to duct taping an NT person's mouth shut ... You are taking away our natural language. You make interacting with the world that much harder.

The use of "you" blends the actual individuals in the narrator's past who enforced quiet hands with current and future (presumably nonautistic) readers, suggesting that the generalized audience of the story bears culpability for actions such as "duct-taping" and "taking away" the narrator's language and "making interacting with the world much harder."

Similarly, in Example 8, Hillary ${ }^{16}$ ended the narrative about a nonautistic stranger who grabbed their flapping hands by giving straightforward instructions to the audience:

\section{Example 8}

Go read "Quiet Hands." Stop trying to suppress stimming. It shouldn't be shocking and strange for me to use my body the way it comes naturally to me to do.

In addition to admonishing the reader, Hillary ${ }^{16}$ directed their reader "go read" an important and relevant article and to "stop trying to suppress the stimming." Explicitly referencing the reader through using "you" pronouns and offering directives (as in Example 8), these narratives position the audience in the foreground of the story and position tellers as dynamic agents who are not just in control of their own behaviors but also in a position to direct readers' actions and thoughts. Situating the reader in this way expresses a negative evaluation of a state of affairs and works to persuade the reader that change is needed. ${ }^{24}$ By choosing particular grammatical resources that work to position the self, the tellers are choosing and organizing scenes to express changing identities from passive reception into volitional agency. $^{23}$

According to Goffman's theory of participation frameworks, ${ }^{33}$ a teller assigns participation status to each member of a social gathering. Participation status is assigned not only to the ratified recipients of talk to whom the speaker directs his visual attention but also to unaddressed overhearing bystanders. ${ }^{33} \mathrm{~A}$ narrator can shift relationships among teller, hearer, and bystander by shifting the way the speaker takes alignment with the encompassing participants. Goffman ${ }^{33}$ described specific scenarios such as radio or TV broadcasts, where the speaker addresses an imagined recipient. Because the nature of a blog post prompts readers to respond to and interact with the blogger, the tellers often communicate with an expectation of a response from a reader even if they are not explicitly calling on the readers. Therefore, tellers are always situating their past and current characters and their actual selves in relation to the readers, and the narratives are in fact addressing imagined unratified readers. Often, calling out the audience changes the participation status of the readers from overhearing bystanders to ratified recipients of the tellers' talk. By changing the participation framework of the audience in this way, the tellers are able to direct their message more specifically to a nonautistic actual audience. This works to hold actual readers accountable for the oppressive consequences of upholding normative standards of conduct that prohibit stimming.

\section{Connecting the autistic community and constructing a collective identity}

In addition to expressing transformed and empowered individual identities, the blog posts we examined worked to connect the autistic community and amplify their collective voices, culminating in a sustained resource through which collective identities can continue to be built. In this section, we show how the online spaces function as identity artifacts and how they serve as a forum to connect aligned perspectives about the experience of being autistic and the nature of autism.

Blog posts as identity artifacts. Once a blogger posts their narrative online, these postings occupy digital space that is accessible to anyone with an unrestricted internet connection. Given their relative stability (compared with, e.g., the transience of oral narratives) and widespread availability, blog posts can become identity artifacts. This term refers to "any instrument (sign, material object, embodied practice, etc.) that interactants make use of to shape the identity of an individual or group."34(p199) Identity artifacts then merge and interact with each other, forming what Leander called artifactual wholes, ${ }^{34}$ which individuals can employ to both signify and interpret their identities. Blog spaces include a forum for readers to add commentary, which then become additional identity artifacts. These new artifacts have the capability to strengthen or weaken the previously constructed artifactual wholes. Blog posts can therefore create a space for continuous collaborative identity work, and within these spaces, both individual and collective identities can be constructed.

On Bascom's blog post, commenters thanked Bascom for her contribution and reported back on their own experiences. Each comment then reshaped the artifactual whole, validating Bascom's experience and contributing to her identity as an advocate. In this way, the original blog post, the comments it elicited, and Bascom's follow-up posts created a web of resources that stabilized Bascom's and the larger community's autistic identities. For example, Bascom ${ }^{35}$ acknowledged on her blog that 2 months following her first blog post, the viral responses she received from the autistic community influenced her sense of self:

\section{Example 9}

\begin{abstract}
"My friends can attest to my state that week-headbanging... I told one of them: 'The irony in writing about what I write about is that you write about not-existing, and then you very suddenly exist.' ... but as I adjusted, as I pieced together the history of what happened and approved comments and somehow, strangely, kept existing."
\end{abstract}

Bascom asserted that narrating a past story as a blog post and engaging with the responses of the (largely autistic) audience enabled her to locate herself along a temporal dimension. This process of gathering events into a coherent and meaningful order and reevaluating the meaning of past experiences with respondents allows autistic bloggers to negotiate new identities as autistic self-advocates.

In addition, Bascom ${ }^{35}$ acknowledged that reading the comments helped her adjust to initially overwhelming and bewildering attention. Comments included remarks such as "This post has the power to change an entire failed system," 
"Me too!... People would tell me to stop stimming so instead I started biting my lip and scratching my head until it bled." In follow-up blog posts, Bascom ${ }^{35}$ quoted responses from her readership, explicitly conveying alignment: "Thank you, In my school, it was 'sit on your hands.'... I feel a little less alone" (emphasis in original). Thus, the original narrative "Quiet Hands," the commenters' positive evaluations of this narrative, and Bascom's alignment with the responses of the audience interact to create an artifactual whole. Indeed, Bascom's "Quiet hands" post instigated the production of Loud Hands: Autistic People, Speaking, which was comprised exclusively of autistic advocates, and which Bascom edited. ${ }^{16}$

The same principle of artifactual wholes operates in interaction between the audience and Maxfield Sparrow, a blogger who introduces themselves as an autistic advocate. A mother of an autistic child wrote a blog post on her own blog, saying how Sparrow's stimming narrative changed her perception of her daughter and influenced her decision not to discourage her daughter from stimming. To this blog post, Sparrow $^{36}$ left the following comment:

\section{Example 10}

\begin{abstract}
"I sometimes get asked why I'm willing to put my garbage on display like that. (I'm actually a VERY private person, though one might not realize it from my writing.) You are the answer ... I write for Evie and for all the countless Evies out there."
\end{abstract}

Sparrow $^{36}$ revealed how the audience's responses, such as Evie's mother's blog post, led them to recognize their positive influence on Evie and motivated them to "put [their] garbage on display." Their audience's responses worked to further stabilize their identification as a person who shares their private experiences online to support other autistic individuals. In this way, their original stimming narratives, the response of Evie's mother, and Sparrow's contingent comments on the parent's blog post form artifactual wholes through which Sparrow becomes an outspoken autistic advocate.

Identity artifacts may also serve as identity resources for the wider autistic advocacy community who are free to comment on the post. A commenter replied to Lindsmith's ${ }^{37}$ narrative, "I can't believe all the connections I'm seeing to everyone else's stories. I'm nervous and a little scared but also very excited to finally learn why I am the way I am!!' The "connection," the commenter notices is mutual participation in identity work that condenses into a collective identity of an autistic online community. This collective identity then helps the commenter explore her own identity as an autistic person.

Ideologically aligned perspectives and collective identities. Koller ${ }^{24}$ argued that ideologies shared by people who identify as members of a group may serve as mechanisms for the development of a collective identity. In the blog posts we examined, the bloggers and commenters frequently referenced and endorsed each other's experiences and claims, creating a sense of ideological alignment within the autistic community. For example, Brown ${ }^{38}$ wrote, "When I read this article by Julia Bascom, which so eloquently describes the abusive side of Applied Behavioral Analysis ... I almost cried." Bascom ${ }^{35}$ also wrote, "I was fifteen, and I spent months circling Amanda Baggs' site ... I had found someone like me. When I was fifteen, I stopped being alone.' Similarly, some bloggers frequently cite "Quiet Hands" or straightforwardly advise the audience to go read "Quiet Hands." For instance, Rose ${ }^{13}$ wrote, "if you are unaware of what this phrase means, or of the implications for autistic people, you need to read 'Quiet Hands' by Julia Bascom.' This explicit association conveys the bloggers' willingness to let Bascom's blog post represent their own experiences and therefore shows alignment of ideological perspectives. The frequent and affirmative referencing of each other's blog posts indexes shared experiences, ideological alignment, and subsequently contributes to a collective autistic perspective reached through consensus among the participants.

Reclaiming "stimming". The use of a shared lexis is another discursive means of generating a collective identity, by expressing alignment and/or distancing from a particular social context. ${ }^{23}$ While medical professionals and autism researchers may use clinical terms, such as RRBs or stereotypy to refer to repetitive behaviors, these terms were rarely used by members of the autistic online community that we examined. Instead, these behaviors were almost always referred to as "stimming." The use of different terms for the same type of behaviors indexes a disconnect between autistic individuals and autism researchers in terms of their understanding of the relevance of this behavior to the lives of people with autism. It also reflects the efforts of autistic bloggers to distance themselves from, and protest against, dominant clinical discourses. In Example 11, Lindsmith ${ }^{37}$ defined "stimming" at the outset before starting to recount her childhood experiences:

\section{Example 11}

"Called 'stereotypy' by psychiatrists, stimming refers to: '... a repetitive body movement that self-stimulates one or more senses in a regulated manner' (My favorite definition, from the Autism Wiki)" (emphasis in original).

Lindsmith ${ }^{37}$ placed "stereotypy" in quotation marks to indicate its status as an externally applied label and then endorses Autism Wiki's definition of stimming. Autism Wiki is a website where autistic individuals share their stories and helpful information for each other.

As mentioned in the introduction, instructors of ABA have also used the term "stimming" with a derogatory connotation. For example, "stimming" refers to behaviors that should be reduced or replaced with more social acceptable behaviors during ABA sessions. ${ }^{39}$ However, autistic advocates are reclaiming the word by using "stimming" to refer to their characteristic behaviors, which should be valued and respected, and urging the nonautistic population to regard stimming as socially acceptable.

Instances in which a word was previously applied pejoratively to a minority community, and was then reclaimed as a form of resistance against oppressive social norms, can be found in the discourse of other minority groups. For example, when only heterosexual individuals used "queer" to label the lesbian, gay, bisexual, transgender, queer (LGBTQ) community, the word implied heterosexual privilege and stereotyped representation of the target community. ${ }^{40}$ However, as the LGBTQ community appropriated the term to define themselves, the new use of the word "queer" propelled a shift in 
people's belief system, perception, and identities. ${ }^{40}$ Similarly, by using "stimming" in their own advocacy discourse, autistic individuals are subverting dominant norms and asserting that stimming represents "resisting, speaking, communicating, and doing so in a way that can be very obviously Autistic.", 17

Just as autistic bloggers employed particular grammatical constructions to illustrate a changed identity into an active agent, changes in the collective perception of "stimming" index an emerging collective identity. For example, as evidenced in the quotes, "I developed a lot of shame around stimming",29 or "I also learned that stimming was bad, and passing was good" (Jo's quote), when the bloggers were narrating about their past experience, "stimming" was considered shameful and bad. However, as their current selves who are reflecting on their past experience, stimming was described as "something that many engaged in proudly" and was "empowering,", 29 "wonderful hobby" (Jo), "normal," "healthy," and "fun." 37 These views are in direct opposition to how many professionals regard stimming behavior, a problematic symptom, which needs to be replaced with more socially appropriate behaviors. Relatedly, Hillary ${ }^{16}$ said, "Then, during class, I was flapping, because hey, I stim." This assertion positions stimming as ordinary, everyday, and beyond the reach of social sanctions. Hillary's colloquial use of "hey, I stim" neutralizes the negative and stereotypic denotation of stimming and presents stimming as closely related to who they are as a person, a person who stims.

Also, while describing how their "hands help [their] connect to a world," Rose ${ }^{13}$ said, "Stimming is communication. Did you get that? Let me say it again, until it sinks in. Stimming is communication" (emphasis in original). Not only do they want the reader to know what stimming is for them, they intentionally repeat the phrase "Stimming is communication" to make sure that the readers themselves internalize the connection between stimming and communication. Many autistic individuals replied with personal examples of how their own stimming behaviors help them communicate. Also, one commenter replied, "This is honestly the first time I've read 'stimming is communication'. I had been thinking of stimming as just a nervous response."

\section{Implications}

This study reveals the role of online communities in supporting the emergence of empowered individual and collective autistic identities. Researchers are now aware that autistic voices are underrepresented in autism research and service delivery; autistic discourses in online spaces may be a fruitful means for at least partially filling this gap. ${ }^{3}$ This study adds to only a handful of studies that employ discourse analysis to examine narrative practices (e.g., Bottema-Beutel and Smith $^{41}$ and Solomon ${ }^{42}$ ) or explore the process of identity formation (e.g., Bottema-Beutel and White ${ }^{43}$ and Lester et al. ${ }^{44}$ ) among autistic individuals. As the autistic bloggers were able to negotiate and construct an empowered selfconfident identity in the process of writing and sharing narratives, future studies may investigate the effectiveness of using personal narrative as a form of support for this population. Importantly, identity development is closely tied to the emotional well-being and overall quality of life of individuals with developmental disabilities. ${ }^{45}$ More research on how autistic individuals develop individual and collective identi- ties and how positive autistic identities developed within the online community are being translated into off-line contexts are also warranted. Future studies should continue to examine the complexities of nonnormative experiences (such as stimming) and how these experiences are involved in identity formation.

In the blog posts we examined, the autistic individuals confirmed that clinical definitions of social competence (which do not make space for practices such as stimming) prevented them from expressing their authentic selves. Bottema-Beutel et al. ${ }^{46}$ suggested that the imposition of neurotypical social norms contributes to the isolation and stigmatization of autistic individuals. While there is a prevailing assumption that autistic individuals lack social skills, in this study, we document the practices by which autistic individuals deftly interacted with each other, formed relationships, and created a thriving advocacy community. We suggest that future studies take this evidence of social competence into consideration when investigating the social skills of autistic individuals and adopt a framework that validates diversity and unique strengths and weaknesses.

Finally, our findings further promote conceptualizations of autism as a difference rather than as inherently comprised of deficiencies, and this has immediate implications for practice. Researchers, policymakers, and other stakeholders could be supported in incorporating this paradigm shift into their own work when providing supports or interventions for this community. In terms of the present findings, understanding the significance of stimming to autistic identity should be considered when determining whether and in what way stimming will be addressed via intervention. At the very least, stimming should be considered as a potential source of connection with other autistic adults.

\section{Limitations}

When understanding the findings of this study, a few limitations should be considered. First, because this study retrieved and analyzed blog posts that were primarily authored by autistic advocates who are quite visible in the online community, it is likely that our findings are not generalizable to the larger autistic population (indeed, generalization of findings is not usually a focus of discourse analysis work, which examines locally constructed phenomena). Second, the nature of blogging and sharing online narratives necessitates that the included bloggers are able to fluently use a computer and internet to communicate. Third, the majority of the included bloggers identify as female or nonbinary. This pattern reflects the lack of male representation in online community observed in previous studies (Gilmour et al. ${ }^{47}$ and Kapp et al. $^{48}$ ) and warrants future studies investigating the use of online communication of individuals who identify as male. While we acknowledge that online autistic communities are "diverse and heterogeneous,",49(p59) narratives that may have contradicted our findings, but were not located as part of our search procedures, were not addressed in this study because our purpose was to analyze online narratives rather than to represent the autistic community as a whole.

Finally, our data sample consists of only blog posts. Because Bascom's blog post instigated the Loud Hands Project, and the Loud Hands Project inspired many other bloggers to share their experiences on their blogs, it is not surprising that 
narratives of stimming experiences were frequently shared in the format of blog posts. However, it is likely that many individuals, especially those who are less well-known selfadvocates (or who are not self-advocates), shared their experience in a less readily available format such as an online discussion groups or in a forum, and we acknowledge that not including these narratives is a limitation. Future research should be conducted to gather narratives that may be less visible online to understand how stimming experience is communicated and is implicated in identity formation among a more general autistic population.

\section{Conclusion}

This discourse analytic study investigated autistic bloggers' narratives about stimming experiences. By situating the self in relation to story antagonists and to the audience in particular ways, narrators expressed empowered individual identities and voiced opposition to hegemonic and oppressive social norms. Also, the narrators were able to connect the autistic community and enact collective identities through collaborative practices such as constructing ideologically aligned identity artifacts (e.g., the blog posts and their comments) and reclaiming the word, "stimming."

\section{Authorship Confirmation Statement}

The first author identified the narratives, did the primary analysis, and wrote the article. The second author provided supervision throughout the development of the conceptual framework of narrative identify, analysis of the examples, and write-up process. All authors have reviewed and approved the article. The article has been submitted solely to this Journal and is not published, in press, or submitted elsewhere.

\section{Author Disclosure Statement}

No competing financial interests exist.

\section{References}

1. Brownlow C, O'Dell D. Constructing an autistic identity: AS voices online. Ment Retard. 2007;44(5):315-321.

2. Bagatell N. Orchestrating voices: Autism, identity and the power of discourse. Disabil Soc. 2007;22(4):413426.

3. Davidson J. Autistic culture online: Virtual communication and cultural expression on the spectrum. Soc Cult Geogr. 2008;9(7):791-806.

4. Glannon W. Neurodiversity. J Ment Health. 2007;2(2):1-6.

5. Clark J, Van Amerom G. Surplus suffering': Differences between organizational understandings of Asperger's syndrome and those people who claim the "disorder." Disabil Soc. 2007;22(7):761-776.

6. English Oxford Living Dictionary. 12th ed. Online Oxford University Press; 2008. https://en.oxforddictionaries.com/ definition/blog_post; Last accessed August 23, 2018.

7. Brownlow C. Presenting the self: Negotiating a label of autism. J Intellect Dev Disabil. 2010;35(1):14-21.

8. American Psychiatric Association. Diagnostic and Statistical Manual of Mental Disorders, 5th ed. Arlington, Virginia: American Psychiatric Publishing; 2013.

9. Jones RSP, Wint D, Ellis NC. The social effects of stereotyped behavior. J Ment Defic Res. 1990;32:261-268.
10. Dunlap G, Dyer K, Koegel RL. Autistic self-stimulation and intertrial interval duration. Am J Ment Retard. 1983;88: 194-202.

11. MacDonald R, Green G, Mansfield R, et al. Stereotypy in young children with autism and typically developing children. Res Dev Disabil. 2007;28:266-277.

12. Steward RL. Repetitive stereotyped behavior or stimming: An online survey of 100 people on autism spectrum. Paper presented at: IMFAR: International Meeting for Autism Research; May 14, 2015; Salt Lake City, Utah. https:// insar.confex.com/imfar/2015/webprogram/start.html; Last accessed July 23, 2018.

13. Rose J. On Stimming and why "quiet hands"ing an Autistic person is wrong. February 10, 2013. https://thecaffeinate dautistic.wordpress.com/2013/02/10/on-stimming-and-whyquiet-handsing-an-autistic-person-is-wrong; Last accessed June 20, 2018.

14. Bascom J. Quiet Hands. Just Stimming.... October 5, 2011. https://juststimming.wordpress.com/2011/10/05/-quiethands/ \#comments; Last accessed June 20, 2018.

15. Autistic Self Advocacy Network. Loud Hands: Autistic People, Speaking. In: Bascom J, ed. The Autistic Press; 2012.

16. Hillary A. My decision, not yours. Yes, That Too. July 22, 2012. http://yesthattoo.blogspot.com/search?q=stimming+ my+decision; Last accessed June 20, 2018.

17. The Loud Hands Project. http://loudhandsproject.org/about; Last accessed June 20, 2018.

18. Ochs E, Capps L. Living Narrative: Creating Lives in Everyday Storytelling. Cambridge, Massachusetts: Harvard University Press; 2002.

19. Benwell B, Stokoe E. Discourse and Identity. Edinburgh, United Kingdom: Edinburgh University Press; 2006.

20. Bucholtz M, Hall K. Theorizing Identity in Language and Sexuality Research. Lang Soc. 2004;33(4):469-515.

21. Somers M. The narrative constitution of identity: A relational and network approach. Theor Soc. 1993;23(5): 605-649.

22. Riessman C. Analysis of personal narratives. In: Gubrium JF, Holstein JA, eds. Handbook of Interview Research. Thousand Oaks, California: Sage; 2002;695-710.

23. Capps L, Ochs E. Constructing Panic: The Discourse of Agoraphobia. Cambridge: Harvard University Press; 1995.

24. Koller V. How to analyze collective identity in discourse: Textual and contextual parameters. CADAAD. 2012;5(2): 19-38.

25. Van Dijk T. Discourse and Context: A Socio-cognitive Approach. Cambridge, United Kingdom: Cambridge University Press; 2008.

26. Leekam SR, Prior MR, Uljarevic M. Restricted and repetitive behaviors in autism spectrum disorders: A review of research in the last decade. Psychol Bull. 2011;137(4):562-93.

27. Fleischmann A, Miller EC. Online narratives by adults with ADHD who were diagnosed in adulthood. Learn Disabil $Q$. 2013;36:47-60.

28. Marcus MA, Westra HA, Eastwood JD, Barnes KL, Mobilizing Minds Research Group. What are young adults saying about mental health? An analysis of Internet blogs. $J$ Med Internet Res. 2012;141:17.

29. Lynn E. THAT'S NOT WHAT MAKES ME CRAZY, PART 2. A Post-Structural Autistic. June 11, 2014. https:// apoststructuralautistic.wordpress.com/2014/06/11/thatsnot-what-makes-me-crazy-part-2; Last accessed June 20, 2018. 
30. Van Leeuwen T. The representation of social actors in discourse. In: Caldas-Coulthard CR, Coulthard M, eds. Text and Practices: Readings in Critical Discourse Analysis. London: Routledge; 1996;32-70.

31. Figueiredo DC. Narrative and identity formation: An analysis of media personal accounts from patients of cosmetic plastic surgery. In: Bazerman C, Bonini A, Figueiredo D, eds. Genre in a Changing World. Fort Collins, Colorado: Parlor Press; 2009;259-280.

32. Kim A. Speaking "out": Ideologies, identities, and individuals in coming out stories. Online Intersect. 2009;10(1): 239-278.

33. Goffman E. Forms of Talk. Oxford: Blackwell; 1981.

34. Leander KM. Locating Natanya: The situated production of identity artifacts in classroom interaction. Res Teach Eng. 2002;37(2):198-250.

35. Bascom J. Response. Just Stimming.... December 13, 2011. https://juststimming.wordpress.com/2011/12/13/-response; Last accessed June 20, 2018.

36. Sparrow M. Re: The cost of compliance is unreasonable. Love Explosion. January 31, 2013. https://loveexplosions .net/2013/01/30/the-cost-of-compliance-is-unreasonable; Last accessed June 20, 2018.

37. Lindsmith K. Stimming 101, or: How I learned to Stop Worrying and Love the Stim. The Artism Spectrum. May 16, 2014. https://kirstenlindsmith.wordpress.com/2014/05/ 16/stimming-101-or-how-i-learned-to-stop-worrying-andlove-the-stim; Last accessed June 20, 2018.

38. Brown L. Having Loud Hands. Autistic Hoya. January 21, 2012. www.autistichoya.com/2012/01/having-loudhands.html; Last accessed June 20, 2018.

39. Byrne H, Byrne T. Mikey dealing with courts tribunals and politicians. In: Keenan M, Henderson M, Kerr KP. Dillenberger K, eds. Applied Behaviour Analysis and Autism: Building a Future Together. London: Jessica Kingsley Publishers; 2005;225-240.

40. Rand EJ. Reclaiming Queer: Activist and Academic Rhetorics of Resistance. Tuscaloosa, Alabama: University of Alabama Press; 2014.
41. Bottema-Beutel K, Smith N. The interactional construction of identity: An adolescent with autism in interaction with peers. Ling Educ. 2013;24:197-214.

42. Solomon O. Narrative introductions: Discourse competence of children with autistic spectrum disorders. Discourse Stud. 2004;6(2):253-276.

43. Bottema-Beutel K, White R. By the book: An analysis of adolescents with autism spectrum condition co-constructing fictional narratives with peers. J Autism Dev Disord. 2016; 46(2):361-377.

44. Lester JN, Karim K, O’Reilly M. Autism itself actually isn't a disability': Negotiating a "normal" versus "abnormal" autistic identity. Commun Med. 2014;11(2):139-152.

45. Wehmeyer ML, Schalock R. Self-determination and quality of life: Implications for special education services and supports. Focus Except Child. 2001;33(8):1-16.

46. Bottema-Beutel K, Park H, Kim SY. Commentary on social skills training curricula for individuals with ASD: Social interaction, authenticity, and stigma. J Autism Dev Disord. 2018;48(3):953-964.

47. Gilmour L, Schalomon PM, Smith V. Sexuality in a community based sample of adults with autism spectrum disorder. Res Autism Spectr Disord. 2012;6(1):313-318.

48. Kapp SK, Gillespie-Lynch K, Sherman LE, Hutman T. Deficit, difference, or both? Autism and neurodiversity. Dev Psychol. 2013;49(1):59-71.

49. Boellstorff T, Nardi B, Pearce C, Taylor TL. Ethnography and Virtual Worlds: A Handbook of Method. Oxford: Princeton University Press; 2012.

Address correspondence to: So Yoon Kim, MA

Department of Teacher Education, Special Education, and Curriculum and Instruction Lynch School of Education Boston College Chestnut Hill, MA 02467

Email: kimagy@bc.edu 